\title{
Lignin transformation by a versatile peroxidase from a novel Bjerkandera sp. strain
}

\author{
Patrícia Raquel Moreira ${ }^{\mathrm{a}, \mathrm{b}}$, Elsa Almeida-Vara ${ }^{\mathrm{a}}$, \\ Francisco Xavier Malcata ${ }^{\mathrm{b}}$, José Cardoso Duarte ${ }^{\mathrm{a}, *}$ \\ ${ }^{a}$ Departamento de Biotecnologia, Instituto Nacional de Engenharia, Tecnologia e Inovação (INETI), Estrada do Paço do Lumiar, 22, \\ P-1649-038 Lisboa, Portugal \\ ${ }^{\mathrm{b}}$ Escola Superior de Biotecnologia, Universidade Católica Portuguesa, R. Dr. António Bernardino de Almeida, P-4200-072 Porto, Portugal
}

Keywords: Enzyme; Wood material; Gel filtration chromatography

\begin{abstract}
A versatile peroxidase, purified from a novel strain of Bjerkandera sp. (B33/3), was tested for its reactivity on a lignin fraction obtained from straw pulping. The effects of such processing parameters as reaction time, $\mathrm{pH}$, and lignin:enzyme ratio were evaluated. Gel filtration chromatography was employed to characterise the molecular mass distribution of the lignin fragments produced by the enzyme-mediated reaction. Our results have shown that such a versatile peroxidase can directly bring about transformations of lignin, even in the absence of external mediators.
\end{abstract}

\section{Introduction}

Attention has recently been paid to a novel class of ligninolytic peroxidases, versatile peroxidases, which combine typical properties of both manganese and lignin peroxidases, coupled with a broad substrate range (RuizDuenas et al., 1999; Camarero et al., 2000; Martinez, 2002). Such a new class of enzymes has high affinity for manganese and dyes, but is also able to oxidise 2,6dimethoxyphenol (DMP) and veratryl alcohol (VA) in a manganese-independent reaction (Martinez, 2002). Unlike manganese peroxidases that are only able to oxidise phenolic substrates in the presence of manganese, versatile peroxidases are able to oxidise such compounds both in manganese dependent and independent reactions.

Versatile peroxidases have also raised a great deal of interest in the biotechnology field, because they do not seem to require any mediators for substrate oxidation. Most studies to date pertaining to versatile enzymes have focused on characterisation of their oxidation ability

*Corresponding author. Tel.: +351217165 181; fax: + 351217163636 .

E-mail address: jose.duarte@ineti.pt (J.C. Duarte). toward several model compounds; however, little effort has been devoted to demonstrate the activity of the members of this enzyme group on what is thought to be one of its natural substrates, i.e., lignin. There is little data available relating to oxidation of lignin (or ligninderivatives) by versatile peroxidases. A recent communication (Moreira et al., 2001a) has reported results of the first in vitro testing of a versatile peroxidase from Bjerkandera sp. strain BOS55, in biobleaching of a eucalyptus kraft pulp; those authors acknowledged a $6 \%$ reduction in the pulp kappa number, but no further assessment was carried out. This study calls attention to the potential use of versatile peroxidases for applications in the pulp and paper industry, namely modification of lignins.

The presence of lignin, or lignin products resulting from various pulping and bleaching operations in pulp and paper industries, is responsible for the brownish colour of their effluents, which can cause environmental problems; although colour is considered a nonconventional discharge parameter, several countries have already limited colour levels in discharge effluents via strict environmental legislation.

Versatile peroxidases have to date been isolated only from Pleurotus ostreatus, Pleurotus eryngii, Pleurotus 
pulmonarius, Bjerkandera adusta, and Bjerkandera sp. strain BOS55 (Camarero et al., 1996, 1999, 2000; Heinfling et al., 1998a, b, c; Mester and Field, 1998; Ruiz-Duenas et al., 1999, 2001; Giardina et al., 2000). Their pH optima for oxidation of $\mathrm{Mn}(\mathrm{II})(\mathrm{pH}$ 5.0) and aromatic compounds and dyes ( $\mathrm{pH}$ 3.0) are quite different, but are similar to the optima of $\mathrm{MnP}$ and $\mathrm{LiP}$ activities. Pleurotus eryngii produces two versatile peroxidase isoenzymes (PS1 and MnPL1), which can be isolated from distinct culture media (Camarero et al., 1999; Ruiz-Duenas et al., 1999). PS1 presents similar activities on Mn(II), DMP, and methoxy- $p$ hydroquinone, but lower than MnPL1 on VA, $p$-methoxybenzene, and lignin model dimers, hence suggesting a lower redox potential (Ruiz-Duenas et al., 2001). The catalytic properties of Pleurotus and Bjerkandera sp. versatile peroxidases are similar to each other (Martinez, 2002).

During a selection program aimed at isolating new potential lignin degraders, one of the most promising strains, tentatively named B33/3, was further tested and consequently identified as a member of the Bjerkandera genus. Further investigation provided a detailed characterization of B33/3 ligninolytic enzymes, leading to description and molecular characterisation of a novel versatile peroxidase in this genus (Moreira et al., 2001b, 2005, 2006). The direct interaction of the enzyme with natural lignin molecules remains to be demonstrated.

In this research, sulphur-free lignin obtained from a soda straw pulping process was used as substrate for biotransformation studies. Lignin in solution was made to react with the versatile peroxidase, previously isolated from Bjerkandera sp. (B33/3), in the absence of any external mediators. Gel filtration was used to follow the evolution in molecular mass distribution of lignin (Zimmerman et al., 1988). The effects of the prevailing reaction conditions upon the decolourisation processes were studied.

\section{Materials and methods}

\section{Feed stock source}

Sulphur-free lignin was obtained from Granit SA (Lausanne, Switzerland). A versatile peroxidase (named RBP) from a Bjerkandera sp. strain was purified, as described elsewhere (Moreira et al., 2006).

\section{Experimenta Idesign and statistical analysis}

Standard $2^{3}$ full factorial design methodology was used to evaluate the effect of some important parameters on RBP reactions, as detailed in Table 1. The parameters tested were reaction time, initial reaction $\mathrm{pH}$, and lignin:enzyme ratio. Duplicates (i.e., replicates run under the same experimental conditions) were obtained for half of the experiments, and used to estimate the standard error of the overall mean and associated with each major and interaction effects. Significance was set at the 0.05 confidence level, using Fisher's distribution. Statistical analysis was performed using the experimental design module of the STATISTICA v. 5.5 software.

\section{Reaction conditions}

In a typical experiment, the $\mathrm{pH}$ of a lignin preparation $(0.005 \mathrm{~g}$ solubilized in $100 \mathrm{mM} \mathrm{NaOH}$ ) was adjusted to the intended value
Table 1

Processing variables tested (in actual and coded form) pertaining to decolourisation reactions initiated with peroxidase $/ \mathrm{H}_{2} \mathrm{O}_{2}$ systems

\begin{tabular}{lllll}
\hline Variable & & & \multicolumn{2}{l}{ Peroxidase reaction } \\
\cline { 1 - 3 } \cline { 5 - 6 } Actual & Coded & & Level -1 & Level +1 \\
\hline Reaction time (h) & 1 & & 2.0 & 4.0 \\
pH & 2 & & 4.0 & 5.3 \\
Lignin:enzyme ratio (w/w) & 3 & & 800 & 1500 \\
\hline
\end{tabular}

Table 2

Decolourisation yields obtained in the various experiments pertaining to decolourisation reactions initiated with peroxidase $/ \mathrm{H}_{2} \mathrm{O}_{2}$ systems ${ }^{\mathrm{a}}$

\begin{tabular}{lllllll}
\hline \multirow{2}{*}{ Run } & \multicolumn{2}{l}{ Variable } & & & \multicolumn{2}{c}{ Decolourisation yield (\%) } \\
\cline { 2 - 3 } \cline { 6 - 7 } & 1 & 2 & 3 & & 1st replicate & 2nd replicate \\
\hline 1 & -1 & -1 & -1 & & 57.5 & - \\
2 & +1 & -1 & -1 & 55.7 & 61.2 \\
3 & -1 & +1 & -1 & & 0.0 & - \\
4 & +1 & +1 & -1 & & 0.0 & 11.8 \\
5 & -1 & -1 & +1 & 66.7 & 68.5 \\
6 & +1 & -1 & +1 & 74.9 & - \\
7 & -1 & +1 & +1 & 10.1 & - \\
8 & +1 & +1 & +1 & 44.7 & 50.6 \\
\hline
\end{tabular}

${ }^{a}$ Replicate values result from two independent experiments.

(4.0 or 5.3) with $100 \mathrm{mM}$ sodium tartrate buffer; the appropriate amount of RBP was then added to reach the desired lignin:enzyme ratio $(800: 1$ or $1500: 1)$. The final volume $(5 \mathrm{~mL})$ of the assay aliquot was made up with the same buffer. The reaction was started with addition of $0.05 \mathrm{~mL}$ of $20 \mathrm{mM}$ hydrogen peroxide. The reaction was conducted at $30^{\circ} \mathrm{C}$, under stirring at $90 \mathrm{rpm}$, for the appropriate period $(2.0$ or $4.0 \mathrm{~h})$, during which $0.05 \mathrm{~mL}$ of $20 \mathrm{mM}$ hydrogen peroxide was added every $60 \mathrm{~min}$. At the end of the reaction, the medium was filtered through Whatman no. 1 (Middlesex, UK) filter paper and the supernatant taken for analysis. Controls were done at the two $\mathrm{pH}$ values tested (4.0 and 5.3), in the presence and absence of the denatured enzyme. The enzyme was denatured by heating to $106{ }^{\circ} \mathrm{C}$ for $10 \mathrm{~min}$. No difference in the decolourisation reaction was observed in the absence or presence of the denatured enzyme. Following the experimental design methodology, 12 runs $(8$ different conditions and 4 replicas) were carried out (see Table 2) and analysed against the controls.

\section{Reaction features}

The reaction of lignin, as catalysed by our enzyme, was quantified via decrease in the true colour of samples (20-fold diluted in $100 \mathrm{mM} \mathrm{NaOH}$ ), determined at $455 \mathrm{~nm}$ using a DR/1020 colorimeter (Hach, Loveland, $\mathrm{OH}$, USA). This method, also employed routinely in the pulp and paper industries to measure the true colour of effluents containing lignin in APHA Pt-Co colour units, was performed according to manufacturer's instructions. The apparent reaction yield was calculated based on decolourisation of reaction samples, with reference to control samples.

The molecular mass distribution of the soluble fragments of lignin (which is correlated with the true colour of the sample) was determined by gel filtration chromatography in a $40 \times 2.5$-cm Sephadex G-100 column (Sigma-Aldrich, St. Louis, MO, USA); elution was at $0.5 \mathrm{~mL} \mathrm{~min}^{-1}$, using $100 \mathrm{mM} \mathrm{NaOH}$ ( $\mathrm{pH} \mathrm{13)}$ ) as eluant; the effluent was monitored spectrophotometrically at $280 \mathrm{~nm}$. The gel filtration system was calibrated with 
proteins of known molecular mass (Bio-Rad, Hercules, CA, USA). Aliquots $(1 \mathrm{~mL})$ of 2 -fold dilutions of filtered samples were injected directly onto the column.

\section{Results}

The experimental results are presented in Table 2, in terms of decolourisation yields. Estimated standard errors were employed to assess the significance level of the effect associated with each processing parameter. The results of the statistical analysis are depicted in Table 3. Changes were observed in the response of the dependent variable (decolourisation yield) as variable conditions (reaction time, $\mathrm{pH}$, and lignin:enzyme ratio) changed from level -1 to level +1 . The main effect values depicted in Table 3 show that the increase in $\mathrm{pH}$ from level -1 to level +1 caused an estimated decrease in decolourisation yield (dependent variable) of ca. 49.8. Unlike $\mathrm{pH}$, changes in the other two processing parameters (reaction time and lignin:enzyme ratio) from level -1 to level +1 produced an estimated increase in the decolourisation yield of ca. 12.9 and 20.6, respectively. Interactions between each two of the three variables tested are relevant, though estimated effects (increases between 7.4 and 9.5) were much lower when compared to effects of each processing variable independently, as reported previously.

A gel filtration chromatography was performed with the objective of evaluating the molecular weight distribution of soluble lignins resulting from the enzymatic reactions. The results of gel filtration chromatography of the lignin solution, obtained from the set of experimental conditions that yielded higher decolourisation, as well as a control sample, are presented in Fig. 1. From the analysis of the chromatogram it is possible to distinguish a notable change

\section{Table 3}

Quantitative effects of each processing variable (and associated standard error) and of corresponding interactions pertaining to decolourisation reactions initiated with peroxidase $/ \mathrm{H}_{2} \mathrm{O}_{2}$ systems

\begin{tabular}{lc}
\hline Effect $^{\mathrm{a}}$ & $\begin{array}{l}\text { Estimate } \pm \text { Standard } \\
\text { error }\end{array}$ \\
\hline Average & $40.8 \pm 1.5^{\mathrm{b}}$ \\
& \\
Main effects of variables & \\
(1) Reaction time (h) & $12.9 \pm 3.1^{\mathrm{d}}$ \\
(2) $\mathrm{pH}$ & $-49.8 \pm 3.1^{\mathrm{d}}$ \\
(3) Lignin:enzyme ratio (w/w) & $20.6 \pm 3.1^{\mathrm{d}}$ \\
& \\
Two-factor interactions of variables & \\
$1 \times 2$ & $8.8 \pm 3.1$ \\
$2 \times 3$ & $9.5 \pm 3.1$ \\
$1 \times 3$ & $7.4 \pm 3.1$ \\
\hline
\end{tabular}

${ }^{\text {a }}$ Change in the response of the dependent variable (decolourisation) as variable conditions change from level -1 to level +1 .

${ }^{\mathrm{b}}$ Standard error based on 8 degrees of freedom.

${ }^{\mathrm{c}}$ Effect of each processing parameter independently.

${ }^{\mathrm{d}}$ Standard error based on 4 degrees of freedom.

${ }^{\mathrm{e}}$ Effect of interactions between each two parameters.

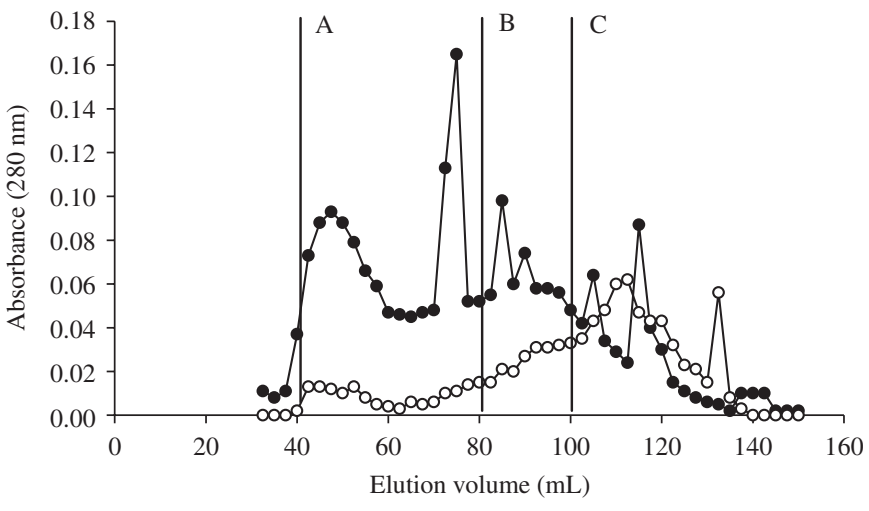

Fig. 1. Gel permeation chromatogram of samples obtained from the control $(\mathrm{pH} \mathrm{4.0)}(\bigcirc)$ and from run $6(\bigcirc)$, for decolourisation reactions initiated with peroxidase $/ \mathrm{H}_{2} \mathrm{O}_{2}$ systems: (A) excluded lignin fragments above $158 \mathrm{kDa}$; (B) separated lignin fragments between 158 and $44 \mathrm{kDa}$; (C) separated lignin fragments below $44 \mathrm{kDa}$.

in the molecular weight distribution of soluble lignin, a strong indication that these changes are dependent on enzymatic reactions (in optimal conditions).

\section{Discussion}

Lignin transformations brought about by this versatile peroxidase were detected and quantified by measuring changes in the true colour of the system solution. The enzyme may catalyse polymerisation, chromophore alteration, or breakdown of lignin molecules. Although all those three reactions may occur, polymerisation reactions leading to precipitation should contribute more for higher decolourisation of samples. The polymerisation of soluble lignin fragments, mostly those of higher molecular weight, as suggested by the gel filtration chromatography analysis, produces high-molecular-mass lignin molecules, which form colloidal particles that tend to precipitate even at high $\mathrm{pH}$. Formation of a (brown) precipitate leads to removal of high-molecular-mass lignins from solution, hence reducing its true colour, as suggested elsewhere (Guerra et al., 2000).

In the experimental design used, all variables affected the reaction response (Table 3); however, the strongest effect was associated with $\mathrm{pH}$ : The higher the $\mathrm{pH}$, the lower the decolourisation extent. This effect can be explained in two ways: (i) the optimum $\mathrm{pH}$ for oxidation of lignin by RBP is on the acidic side, as with the oxidation of VA (Moreira et al., 2006); and (ii) lignin has a lower solubility at acidic $\mathrm{pH}$, so macromolecules formed by putative polymerisation will precipitate earlier at a lower $\mathrm{pH}$. The relative amounts of lignin and enzyme affected the reaction responses as well; an increase in the amount of enzyme added per unit substrate led to a decrease in the decolourisation yield. This result cannot be easily explained, as the opposite should be expected; however, it may be that the higher enzyme/ protein ratio contributes to stabilise the soluble (contributing to colloidal particle formation) and/or also contributes 
to the increase of lignin degradation by the enzyme, thus increasing the resolubilisation of the polymerised fractions. It is also well known that heterogeneous enzymatic catalysis is not a linear function of the enzyme concentration per unit of substrates, as in the case of, for example, lipases (Duarte, 1982). Further evaluation of this effect is needed. Reaction time also affected the reaction extent, hence emphasising the slow and non-equilibrium nature of the reactions; the reaction would likely be carried out further if more time was allowed. Significant interactions between variables seem to occur in this system (Table 3), which is also expected due to the heterogeneous nature of the reaction system, as well as physical and biochemical changes that might occur in the reaction medium. Further studies are needed to fully clarify the mechanistic basis of this complex system, although reactivity is almost certainly due to the generation of free radicals by the enzyme from lignin.

This mechanism is also suggested from inspection of Fig. 1, where it is possible to observe a strong reduction of the high- and intermediate-molecular-mass fractions of the soluble lignin fraction (which might be due to the free radical induced polymerisation reaction, responsible for the brown precipitate observed) and an increase (although smaller) of the lower-molecular-mass fraction of lignin in solution, hence confirming the presence of degradation products, most likely produced by enzymatically catalysed oxidative reactions. Hofrichter et al. (2001) have also reported that enzymatic attack by a $\mathrm{MnP}$ enzyme from Phlebia radiata on milled pine wood resulted in polymerisation of lower-molecular-mass soluble wood components, as well as partial depolymerisation of the insoluble bulk of pine wood. These results are in agreement with those obtained in our present research, but differ in that, unlike $\mathrm{MnP}$, this versatile peroxidase does not require manganese for effective action. Complementary studies on lignin molecular structure in various fractions, although of great complexity, should contribute to the clarification of the enzymatic reaction mechanisms involved in polymerisation and degradation.

\section{Conclusions}

Our results have shown, for the first time, that a versatile peroxidase (RBP) is able to react with soluble lignin fragments in the absence of added mediators, most probably causing extensive polymerisation of high and intermediate fractions of lignin, and an increase of the small-molecular-mass lignin fraction (probably due to degradation). The results also show that Bjerkandera sp. $\mathrm{B} 33 / 3$ versatile peroxidase may be of interest for use in pulp and paper industries.

\section{Acknowledgements}

Granit SA is hereby gratefully acknowledged for having made available the sulphur-free lignin tested in this work.
Author Moreira was sponsored by a doctoral fellowship (PRAXIS XXI/BD/15825/98), granted by FCT (Portugal).

\section{References}

Camarero, S., Bockle, B., Martinez, M.J., Martinez, A.T., 1996. Manganese-mediated lignin degradation by Pleurotus pulmonarius. Applied and Environmental Microbiology 62, 1070-1072.

Camarero, S., Sarkar, S., Ruiz-Duenas, F.J., Martinez, M.J., Martinez, A.T., 1999. Description of a versatile peroxidase involved in the natural degradation of lignin that has both manganese peroxidase and lignin peroxidase substrate interaction sites. Journal of Biological Chemistry 274, 10324-10330.

Camarero, S., Ruiz-Duenas, F.J., Sarkar, S., Martinez, M.J., Martinez, A.T., 2000. The cloning of a new peroxidase found in lignocellulose cultures of Pleurotus eryngii and sequence comparison with other fungal peroxidases. FEMS Microbiology Letters 191, 37-43.

Duarte, J.M.C., 1982. The enzymic oxidation of cholesterol in the presence of water immiscible solvents. Ph.D. Thesis, University of London, 319pp.

Giardina, P., Palmieri, G., Fontanella, B., Rivieccio, V., Sannia, G., 2000. Manganese peroxidase isoenzymes produced by Pleurotus ostreatus grown on wood sawdust. Archives of Biochemistry and Biophysics 376, 171-179.

Guerra, A., Ferraz, A., Cotrim, A.R., da Silva, F.T., 2000. Polymerization of lignin fragments contained in a model effluent by polyphenoloxidases and horseradish peroxidase/hydrogen peroxide system. Enzyme and Microbial Technology 26, 315-323.

Heinfling, A., Martinez, M.J., Martinez, A.T., Bergbauer, M., Szewzyk, U., 1998a. Purification and characterization of peroxidases from the dye-decolorizing fungus Bjerkandera adusta. FEMS Microbiology Letters $165,43-50$.

Heinfling, A., Martinez, M.J., Martinez, A.T., Bergbauer, M., Szewzyk, U., 1998b. Transformation of industrial dyes by manganese peroxidases from Bjerkandera adusta and Pleurotus eryngii in a manganeseindependent reaction. Applied and Environmental Microbiology 64, 2788-2793.

Heinfling, A., Ruiz-Duenas, F.J., Martinez, M.J., Bergbauer, M., Szewzyk, U., Martinez, A.T., 1998c. A study on reducing substrates of manganese-oxidizing peroxidases from Pleurotus eryngii and Bjerkandera adusta. FEBS Letters 428, 141-146.

Hofrichter, M., Lundell, T., Hatakka, A., 2001. Conversion of milled pine wood by manganese peroxidase from Phlebia radiata. Applied and Environmental Microbiology 67, 4588-4593.

Martinez, A.T., 2002. Molecular biology and structure-function of lignindegrading heme peroxidases. Enzyme and Microbial Technology 30, 425-444.

Mester, T., Field, J.A., 1998. Characterization of a novel manganese peroxidase-lignin peroxidase hybrid isozyme produced by Bjerkandera species strain BOS55 in the absence of manganese. Journal of Biological Chemistry 273, 15412-15417.

Moreira, M.T., Sierra-Alvarez, R., Lema, J.M., Feijoo, G., Field, J.A., 2001a. Oxidation of lignin in eucalyptus kraft pulp by manganese peroxidase from Bjerkandera sp. strain BOS55. Bioresource Technology 78, 71-79.

Moreira, P.R., Almeida-Vara, E., Sena-Martins, G., Polonia, I., Malcata, F.X., Duarte, J.C., 2001b. Decolourisation of Remazol Brilliant Blue $\mathrm{R}$ via a novel Bjerkandera sp. strain. Journal of Biotechnology 89, $107-111$.

Moreira, P.R., Duez, C., Dehareng, D., Antunes, A., Almeida-Vara, E., Frère, J.M., Malcata, F.X., Duarte, J.C., 2005. Molecular characterisation of a versatile peroxidase from a Bjerkandera strain. Journal of Biotechnology 118, 339-352.

Moreira, P.R., Bouillenne, F., Almeida-Vara, E., Malcata, F.X., Frère, J.M., Duarte, J.C., 2006. Purification, kinetics and spectral characterisation of a new versatile peroxidase from a Bjerkandera sp. isolate. Enzyme and Microbial Technology 38, 28-33. 
Ruiz-Duenas, F.J., Martinez, M.J., Martinez, A.T., 1999. Molecular characterization of a novel peroxidase isolated from the ligninolytic fungus Pleurotus eryngii. Molecular Microbiology 31, 223-235.

Ruiz-Duenas, F.J., Camarero, S., Perez-Boada, M., Martinez, M.J., Martinez, A.T., 2001. A new versatile peroxidase from Pleurotus. Biochemical Society Transactions 29, 116-122.
Zimmerman, W., Paterson, A., Broda, P., 1988. Conventional and high performance size exclusion chromatography of graminaceous lignin carbohydrate complexes. In: Wood, W.A., Kellogs, S.T. (Eds.), Methods in Enzymology, vol. 141. Academic Press, San Diego, CA, pp. 191-199. 